Special issue of the 3rd International Conference on Computational and Experimental Science and Engineering (ICCESEN 2016)

\title{
Structural Alterations in Smithsonite during High-Energy Ball Milling
}

\author{
T. TunÇ PARLAK ${ }^{a *}$, V.M. YILMAZ ${ }^{b}$ And K. Yildiz ${ }^{a}$ \\ ${ }^{a}$ Sakarya University, Metallurgy and Materials Engineering, Sakarya, Turkey \\ ${ }^{b}$ Bartin University, Central Researching Laboratory, Bartin, Turkey
}

\begin{abstract}
Smithsonite, $\mathrm{ZnCO}_{3}$, from Zamantı-Kayseri, Turkey, was subjected to high-energy milling. X-ray diffraction analysis was performed to study amorphisation in the structure and the alterations of bands in the structure were investigated by Fourier transform infrared spectroscopy. Characterization of milled smithsonite by X-ray diffraction analysis has shown that disappearance, decrease and/or shifting of the patterns occurred with mechanical activation, which means that amorphisation was taking place. Amorphisation was also demonstrated by Fourier transform infrared spectroscopy analysis, where shifting of band centers was observed.
\end{abstract}

DOI: 10.12693/APhysPolA.132.723

PACS/topics: 61.43.Gt, 81.20.Wk, 91.60.Ed

\section{Introduction}

Zinc sulfide ores, which can be easily separated from gangue and upgraded by flotation, are the most important conventional sources of zinc. As the secondary minerals, zinc oxide ores whose zinc bearing minerals are mainly various carbonate and silicates minerals, such as smithsonite $\left(\mathrm{ZnCO}_{3}\right)$, hydrozincite $\left(2 \mathrm{ZnCO}_{3} \cdot 3 \mathrm{Zn}(\mathrm{OH})_{2}\right)$, zincite $(\mathrm{ZnO})$, willemite $\left(\mathrm{Zn}_{2} \mathrm{SiO}_{4}\right)$ and hemimorphite $\left(\mathrm{Zn}_{4} \mathrm{Si}_{2} \mathrm{O}_{7}(\mathrm{OH})_{2} \cdot \mathrm{H}_{2} \mathrm{O}\right)$ are other sources for production of zinc. Because of the decline of zinc sulfides reserves, as well as the restriction on sulfur emission all over the world, zinc oxide ores with a huge reserve are paid attention $[1,2]$. Smithsonite is naturally occurring zinc carbonate. This is one of the secondary minerals of zinc and its formation is controlled by the partial pressure of $\mathrm{CO}_{2}$. Smithsonite is only stable at elevated $\mathrm{CO}_{2}$ partial pressures $[3,4]$.

Mechanical activation by high intensity milling has been commonly used as an effective pretreatment method in various areas, such as mining, metallurgy and materials engineering. In mineral processing, the aim of coarse and fine grinding is to liberate the ore for downstream separation. Furthermore, fine grinding is also used after mineral separation in order to give concentrates the right particle size distribution or a sufficiently high surface area. Mechanical activation aims to enhance a reaction [5]. Mechanical activation of minerals makes it possible to reduce their decomposition temperature or causes a degree of disorder $[6,7]$.

In this study, smithsonite was subjected to high-energy ball milling and disorder in the crystalline structure of smithsonite were investigated using X-ray diffraction (XRD) and Fourier transform infrared analysis (FTIR). Process of obtaining of $\mathrm{ZnO}$ without calcination was also investigated for further hydrometallurgical processes.

*corresponding author; e-mail: ttunc@sakarya.edu.tr

\section{Materials and methods}

Smithsonite, $\mathrm{ZnCO}_{3}$, obtained from Zamant-Kayseri region in Turkey was crushed and sieved through $75 \mu \mathrm{m}$ sieve for standardization of the particle size. Mechanical activation was performed in a Planetary Mono Mill Pulverisette 6 , using tungsten carbide (WC) balls $(10 \mathrm{~mm}$ in diameter) and tungsten carbide (WC) bowl $(250 \mathrm{ml}$ in volume). Ball-to-mass ratio and speed of main disk were kept constant at 20 and $600 \mathrm{rev} \mathrm{min}^{-1}$ respectively. Activated and non-activated smithsonite samples were characterized by means of X-ray diffraction analysis (Rigaku SmartlabTM X-ray Diffractometer) and Fourier transform infrared spectroscopy (Shimadzu).

\section{Results and discussion}

$\mathrm{X}$-ray diffraction analysis of non-activated smithsonite and smithsonite samples activated for 15, 30 and 60 min are given in Fig. 1. As seen from this figure, intensity of smithsonite peaks tended to decrease with milling time, such as peaks positioned at $25.14^{\circ}, 32.64^{\circ}$ and $38.74^{\circ}$. It was stated that after extended milling, line broadening and disappearance of diffraction peaks take place in $\mathrm{X}$-ray patterns, which mean the formation of metastable, amorphous phase, because of the development of large number of dislocations. Their associated strain fields may lead to an overall decrease in long-range lattice periodicity $[7,8]$. In addition, smithsonite peaks got lost after $60 \mathrm{~min}$ of mechanical activation and $\mathrm{ZnO}$ peaks were detected after 15 min of high-energy milling. It was detected from XRD analysis that smithsonite had decomposed and $\mathrm{ZnO}$ occurred during high-energy milling.

The entire Fourier transform infrared spectra of nonactivated and activated smithsonite for different milling times are shown in Fig. 2a. Figure $2 \mathrm{~b}$ and $2 \mathrm{c}$ represents the intervals of $2000-1000 \mathrm{~cm}^{-1}$ and $1000-400 \mathrm{~cm}^{-1}$, respectively, which are given separately for understanding of the alteration occurring with mechanical activation.

For non-activated sample, positions of intense bands are at $1425.45 \mathrm{~cm}^{-1}, 869.93 \mathrm{~cm}^{-1}$ and $744.55 \mathrm{~cm}^{-1}$. 

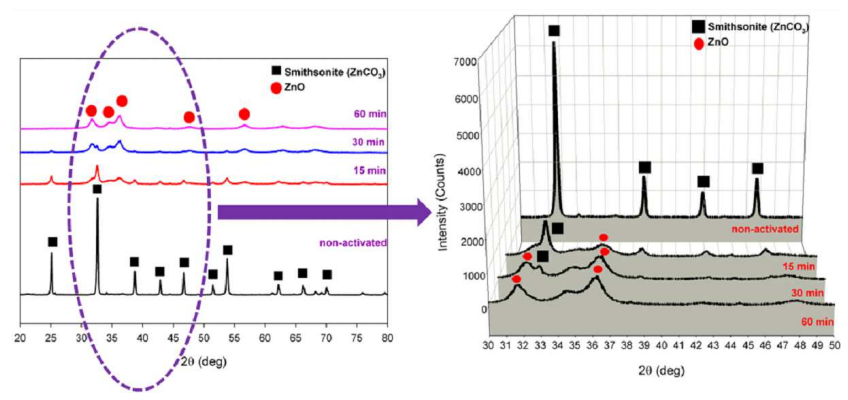

Fig. 1. XRD analysis of non-activated and activated smithsonite.
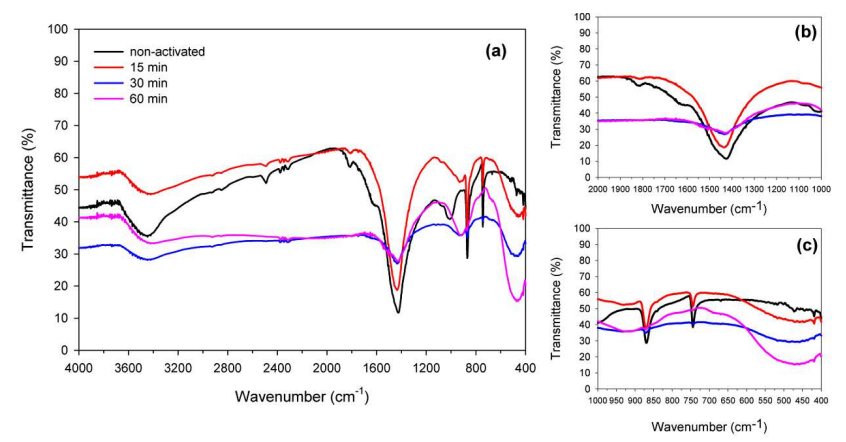

Fig. 2. (a) FTIR analysis of non-activated and activated smithsonite (b) $2000-1000 \mathrm{~cm}^{-1}$ region of FTIR and (c) $1000-400 \mathrm{~cm}^{-1}$ region of FTIR.

These bands correspond to $v_{3}$, asymmetric stretching of $\left(\mathrm{CO}_{3}\right)^{2-}, v_{2}$, bending mode of carbonate and $v_{4}$, in phase bending mode of carbonate, respectively $[9,10]$. In Fig. 2b transmittance change of $1437.03 \mathrm{~cm}^{-1}$ band is shown. This band is about to wither after the mechanical activation time of 30 and 60 min. Same phenomenon takes place for $869.93 \mathrm{~cm}^{-1}$ and $744.55 \mathrm{~cm}^{-1}$ bands. However $744.55 \mathrm{~cm}^{-1}$ band gets lost after $15 \mathrm{~min}$ of mechanical activation.

The other important alteration in spectrum has occurred at $\sim 472 \mathrm{~cm}^{-1}$. As seen from Fig. 2a and 2c, this band, which is defined as the characteristic band of $\mathrm{ZnO}$ [11], becomes stronger with mechanical activation. Other weaker bands of non-activated sample are positioned at $2494.06 \mathrm{~cm}^{-1}$ and $2852.84 \mathrm{~cm}^{-1} .2494 .06 \mathrm{~cm}^{-1}$ band is assigned to a combination of the $v_{2}$ and $v_{3}$ vibrational modes. It is said that $2852.84 \mathrm{~cm}^{-1}$ band may arise from the first fundamental overtone of the $v_{3}$ band at around $1437 \mathrm{~cm}^{-1}$ [9]. Both these bands were getting weaker and had disappeared with increased mechanical activation duration, as shown in Fig. 2a. A broad band, centered at $3446.94 \mathrm{~cm}^{-1}$ for non-activated sample, corresponds to adsorbed water [10]. Transmittance of bands that correspond to carbonate anion has changed, decreased and disappeared with mechanical activation. But the $\sim 472 \mathrm{~cm}^{-1}$ centered band became stronger with mechanical activation, which means that the decomposition of smithsonite had occurred during milling.

\section{Conclusions}

Results of X-ray diffraction analysis show that the peaks of smithsonite decreased during high-energy ball milling and disappeared completely after $60 \mathrm{~min}$ of mechanical activation. Fourier transform infrared spectroscopy of non-activated and activated smithsonite also show that a decrease and/or shifting of the patterns occur during mechanical activation and that the transmittance of bands of carbonate anion was decreasing and disappeared. As a result, decomposition of smithsonite into $\mathrm{ZnO}$ occurs during high-energy ball milling.

\section{References}

[1] Y. Zhang, J. Deng, J. Chen, R. Yu, X. Xing, Hydrometallurgy 131-132, 89 (2013).

[2] A.H.N. Kashani, F. Rashchi, Miner. Eng. 21, 967 (2008).

[3] M.C. Hales, R.L. Frost, J. Thermal Anal. Calorimetry 91, 855 (2008).

[4] R.L. Frost, M.C. Hales, D.L. Wain, J. Raman Spectroscopy 39, 108 (2008).

[5] J. Li, M. Hitch, Miner. Eng. 86, 24 (2016).

[6] P. Balaz, Mechanochemistry in Nanoscience and Minerals Engineering, Springer-Verlag, Berlin, 2008.

[7] T. Tunç, F. Apaydin, K. Yildiz, J. Thermal Anal. Calorimetry 118, 883 (2014).

[8] D. Tromans, J.A. Meech, Miner. Eng. 14, 1359 (2001).

[9] R.L. Frost, W.N. Martens, D.L. Wain, M.C. Hales, Spectrochim. Acta A 70, 1120 (2008).

[10] M.C. Hales, R.L. Frost, Polyhedron 26, 4955 (2007).

[11] C.Yan, D. Xue, J. Alloys Compd. 431, 241 (2007). 